\title{
First record of leucism in Mantled Howler Monkeys Alouatta palliata (Gray 1849)
}

\author{
Cristian Barros-Diaz ${ }^{1}$, Silvia Vela ${ }^{1}$, Abel Gallo-Perez ${ }^{1}$, Manuel Chiquito ${ }^{1}$, Xavier Cornejo ${ }^{2}$, \\ Denis Mosquera-Muñoz ${ }^{1}$, and Julian Perez-Correa ${ }^{1}$ \\ ${ }^{1}$ Fundación para la Conservación e Investigación JaPu \\ ${ }^{2}$ Universidad de Guayaquil Facultad de Ciencias Naturales
}

January 11, 2022

\begin{abstract}
The existence of chromatic aberrations such as leucism or albinism is the result of inbreeding in isolated populations of wild local fauna and is associated with environmental stressors. This anomaly may reduce survival rates. There are many cases of leucism in wildlife, but overall, it is considered very rare. In neotropical primates, there have been records of leucism but previously, in howler monkeys was unknown. In this article, we report for the first time leucistic young individuals of Mantled howler monkeys Alouatta palliata, subspecies A. p. aequatorialis in an isolated remanent of tropical dry forest in southwestern Ecuador, namely Cerro Blanco Protective Forest. In total, we found two individuals, we named them Albita (a female) and Japu (a male). We also include a spatial analysis of the covert forest loss between 2000 to 2020. The report of individuals with leucism, may imply inbreeding because of isolated populations. Thus, immediate management strategies must be considered to significantly increase connectivity with other populations of howler monkeys.
\end{abstract}

\section{Hosted file}

Barros_etal_FirstLeucism.docx available at https://authorea.com/users/454976/articles/552433first-record-of-leucism-in-mantled-howler-monkeys-alouatta-palliata-gray-1849 

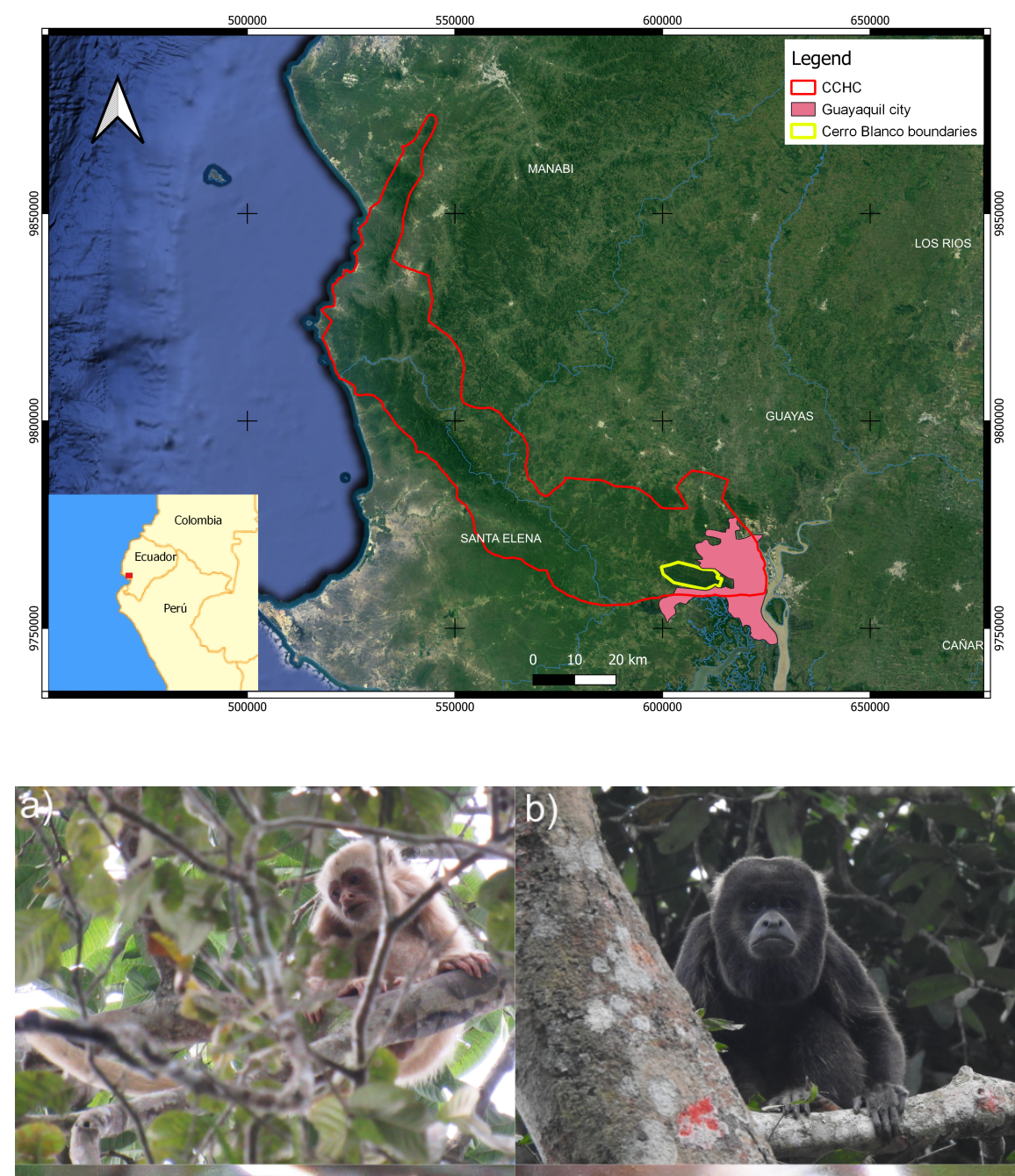

c)

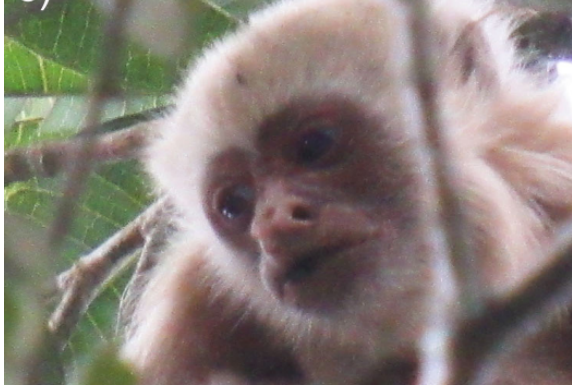

d) 

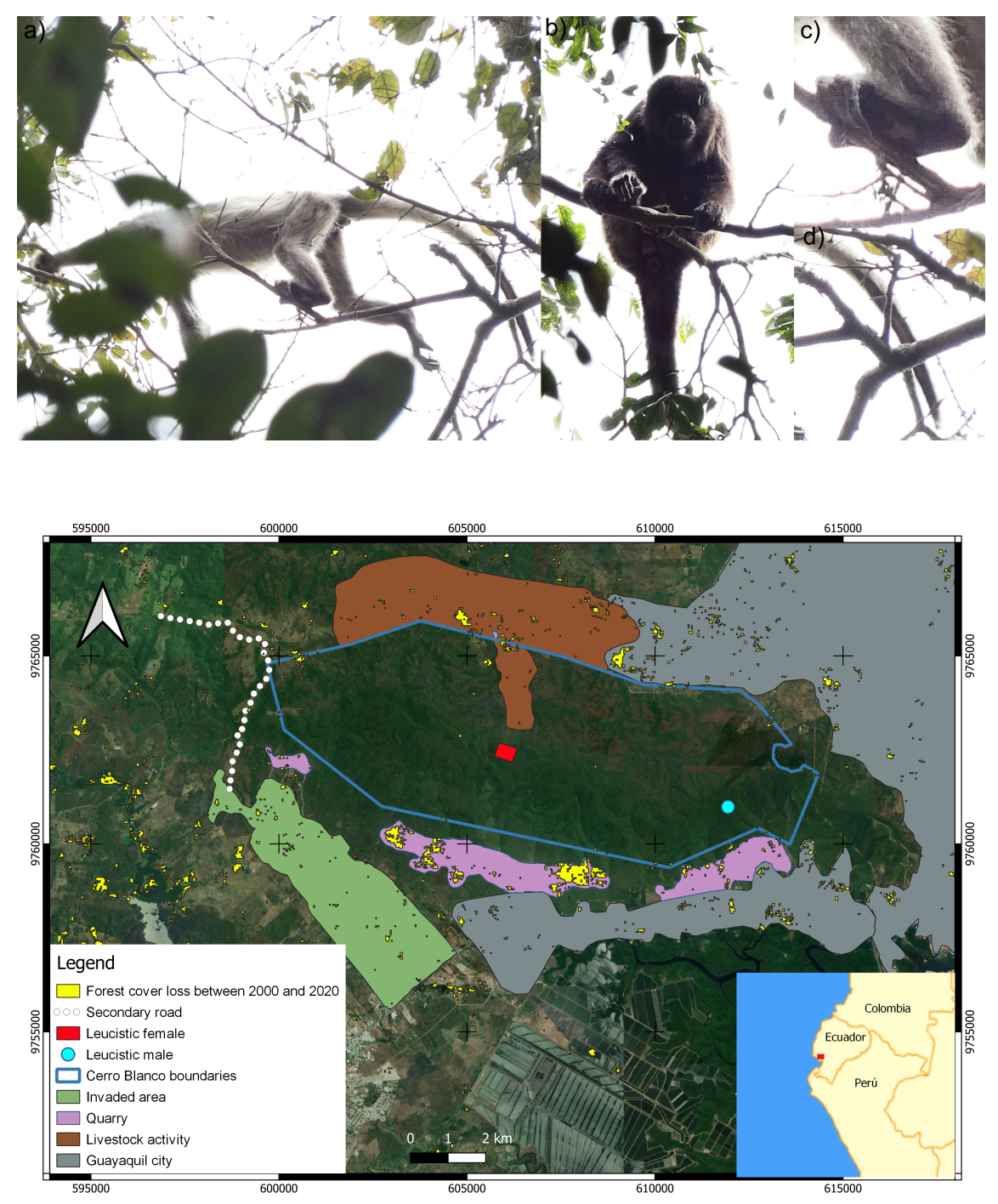